\title{
The New Tools for a Global Survey of Potential Sites for the Future Giant Telescopes
}

\author{
Marc Sarazin $^{* a}$, Edward Graham ${ }^{\mathrm{b}}$, Martin Beniston ${ }^{\mathrm{b}}$, Michael Riemer ${ }^{\mathrm{c}}$ \\ (a) European Southern Observatory, (b) University of Fribourg, (c) Meteorological Institute of \\ Munich
}

\begin{abstract}
The siting of future giant telescopes poses a challenge to the astronomical community. Some of the top level existing observatories are already too crowded; others do not meet the specifications on particular environmental parameters such as wind or seismicity.

On the other hand it has been proven that continental sites can be as good as islands, opening the way for many candidates not yet properly studied. To operate a pre-selection, it is proposed to implement a dedicated geographical information system (GIS) handling the wealth of available remote sensing data worldwide. When focusing onto particular summits, the GIS should then be complemented by mesoscale modeling of the local flow.
\end{abstract}

Some examples are given to support this strategy.

Keywords: Site survey, Geographical Information Systems, Mesoscale modeling

\section{INTRODUCTION}

The site survey for OWL poses the challenge of defining a long term strategy which shall be able to evolve with the developments of the engineering concepts. It is indeed not possible, as in past projects, to select the best available site on the basis of cloudiness and seeing only, and to set the design specifications of the telescope in accordance. Some particularities of gigantic structures as well as the continuous use of adaptive optics impose new dramatic requirements, in particular the sensitivity to seismic hazard of the telescope structure in survival mode could eliminate many of the existing top-level observatories. Similarly the limiting operational wind speed for the telescope mechanics and optics shall be a major selection criterion; wind analysis studies of the OWL design are underway (1). Finally, the performance, and in some cases even the feasibility, of an adaptive optics system for OWL is linked to the temporal coherence of the atmosphere, a highly location dependent parameter, simulations currently undertaken shall set the requirements for the site.

After a thorough review of the regional climatology worldwide, a consistent database shall be assembled into a dedicated geographical information system (GIS) with a higher resolution on the areas of interest. The locations satisfying the engineering requirements shall be compared and ranked in terms of science throughput.

It is also planned to make intensive use of mesoscale models to provide a detailed analysis of the wind flow over selected areas. A study is underway to assess the accuracy of such models, comparing meteorological measurements and modeled data of the wind speed and direction at the VLT observatory of Paranal, clearly showing a flow reversal

* msarazin@eso.org, http://www.eso.org/astclim, European Southern Observatory, D85748 Garching, Germany 
close to ground level which does not appear on large scale maps. The conditions of occurrence of such flow pattern, often linked to bad optical seeing, shall be analyzed, in particular searching for links to global climate change.

Finally, as in any site survey, field measurements have to be conducted on selected candidates. Automated autonomous monitors have to be developed for that purpose on the model of the VLT ASM (VLT Astronomical Site Monitor). Such monitors shall be equipped with traditional meteorological equipment, as well as with dedicated instruments for monitoring seeing, sky photometric quality, isoplanatic angle and coherence time. In addition, single stars turbulence profilers are currently under development (4) to hopefully replace the very accurate, but poorly transportable, traditional SCIDAR. It is hoped that a thorough initial climatic and meteorological analysis described in the next sections allows to shorten the duration of the field campaigns, which in any case could never cover all climatic cycles, some of them being multi-decadal.

\section{TROPOSPHERIC FLOW AS A NEW PARAMETER FOR ELT SITES}

Adaptive optics techniques are sensitive to the rate of change of the optical wave front high spatial frequency structures due to atmospheric turbulence.

The sub-tropical jet stream acts as circulation engine which drags lower layers of the atmosphere in its infernal rotation around the earth. It is thus realistic to assume that whatever their altitude, the velocity of all turbulence layers is somehow linked the $200 \mathrm{mb}$ global circulation. A method described in (2) permits to estimate the wavefront coherence time from a combination of ground based seeing measurements and general circulation data. An excellent agreement was found with VLT interferometer atmospheric phase fluctuations (3). The data summarized in Table 1 show that the ratio between existing observatories and a reference site belonging the inter tropical belt where no jet stream is present is about 2 on average and up to 5 on some months.

\begin{tabular}{|l|l|l|l|l|l|l|}
\hline Site/Country & $\begin{array}{l}\text { Chirripo } \\
\text { Costa Rica }\end{array}$ & $\begin{array}{l}\text { Mauna Kea } \\
\text { Hawaii, USA }\end{array}$ & $\begin{array}{l}\text { Gamsberg } \\
\text { Namibia }\end{array}$ & Paranal Chile & $\begin{array}{l}\text { La Palma } \\
\text { Canary, Spain }\end{array}$ & $\begin{array}{l}\text { Maidanak } \\
\text { Uzbekistan }\end{array}$ \\
\cline { 1 - 4 } Mean Speed (m/s) & 17.8 & 19.5 & 32.0 & 34.5 & 24.0 & 27.1 \\
\hline June & 10.3 & 24.7 & 20.0 & 22.2 & 42.6 & 49.6 \\
\hline Yearly mean & 13.6 & 24.1 & 26.6 & 27.5 & 32.4 & 33.7 \\
\hline
\end{tabular}

Table 1: Comparison of the mean 1980-1995 200 mb wind velocity in $\mathrm{m} / \mathrm{s}$ at various sites for the months of June, December and for the full year (from the 2.5 degree resolution NOAA Global Gridded Upper Air database). 


\section{GEOGRAPHICAL INFORMATION SYSTEM}

\subsection{Preliminary Design}

A contract for appropriate site selection, using a GIS-based (Geographical Information System) decision making tool, has been appointed to the Department of Geosciences, University of Fribourg, Switzerland. The software platform for the decision making tool will be Windows based. It will consist of a robust user interface allowing interrogation of combined climatological, topographical and geological databases. This will be achieved by using a combination of Visual Basic computing language and GIS (geographical information system) software (e.g. IDRISI). Relevant IDRISI modules will be called by accessing the IDRISI Library for that module, without actually running the IDRISI software itself. Depending on the user's preferences, the Visual Basic code will pass any relevant queries to the IDRISI Library, and IDRISI will return the appropriate response for display on the user interface. Figure 1 illustrates this procedure

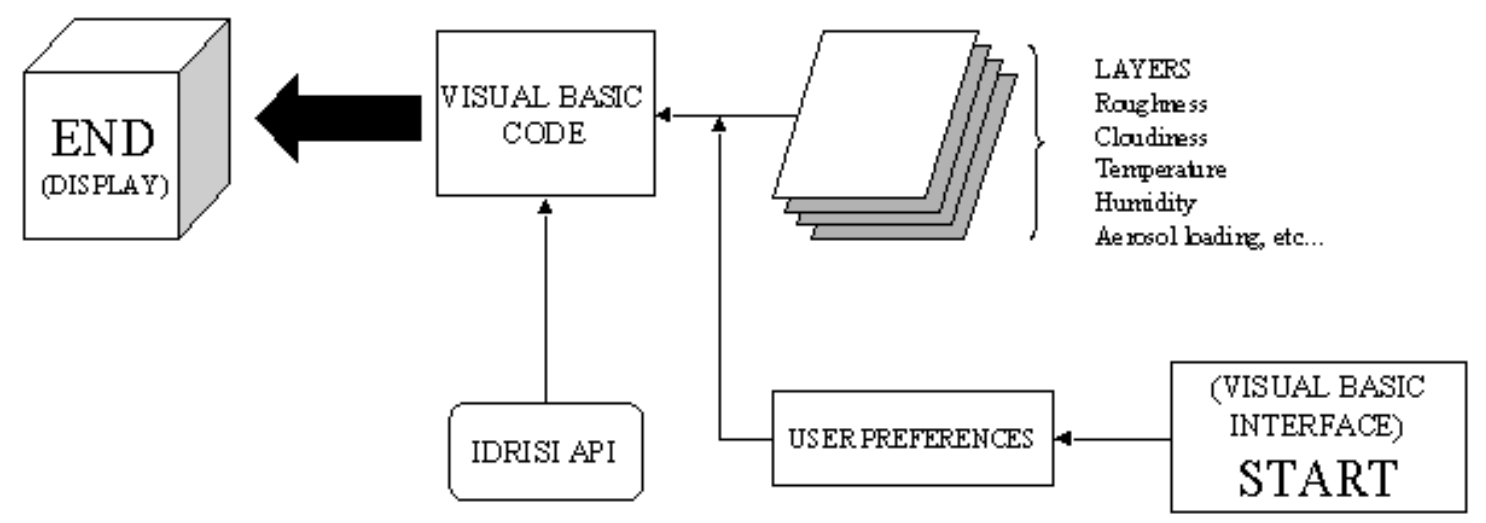

Figure 1: Schematic plan illustrating the events within the GIS decision making tool. The initial interface will be designed in Visual Basic. Depending on user preferences, one or more layers from climatological, topographical and geological databases will be called. Further Visual Basic code will then interrogate the IDRISI library (API). This will be followed by plotting and display of the information on the interface

\subsection{The Climatological Database}

There are many different climatological and meteorological parameters that will need to be considered in the decisionmaking process. Those of primary importance include air temperature, humidity (precipitable water content), surface wind speed and direction, synoptic isobaric flow (at standard levels) and cloud cover. Layers for each of these parameters will be created in the global climatological database, the data for which comes from:

- NCEP / NCAR Global Re-analyses data from the NOAA-CIRES Climate Diagnostics Center in Boulder, Colorado (http://www.cdc.noaa.gov/cdc/data.nmc.reanalysis.html). The NCEP/NCAR Reanalysis project uses a state-of-the-art analysis/forecast system to perform data assimilation using past data from 1948 to the present. The data is available in gridded «NetCDF» format (.nc extension, a standard American compressed binary format used for climatological data). Most climatological and meteorological variables are available at a grid resolution of $2.5^{\circ}$ or greater. A full list of the files used in the construction of the database is given in Table 2 below.

- ECWMF Global Re-analyses (http://www.ecmwf.int). The fifteen year reanalysis dataset between 1979 and 1993 is available on CD-Rom from ECMWF in GRIB format (a standard World Meterological Organisation compressed binary format) under the user-name of ERA-15. Again, data is available at $2.5^{\circ}$ grid resolution (a 
full list is given in Table 1) A new reanalysis project called ERA-40 will cover the period from mid-1957 to 2001. It is expected to become available in early 2003.

Before the data can be used in IDRISI, it must be converted in ASCII or standard binary (uncompressed without headers) formats. Both GRIB and NETCDF are heavily compressed, requiring complex algorithms and calculations to re-establish the original data format. Fortunately, GrADS software accomplishes conversion of NETCDF easily, by using user-defined FORTRAN-like scripts. It is hoped to use WGRIB to achieve the same with the ECMWF data.

\begin{tabular}{|c|c|c|c|c|}
\hline $\begin{array}{l}\text { A) NCEP/NCAR } \\
\text { data }\end{array}$ & & & & \\
\hline File name & Source & Resolution & Period & File description \\
\hline uwnd.mon.mean.nc & $\begin{array}{l}\text { http://www.cdc.noaa } \\
\text {.gov/cdc/data.nmc.re } \\
\underline{\text { analysis.html }}\end{array}$ & $\begin{array}{l}2.5^{\circ} \\
(144 \text { by } 73 \text { pts })\end{array}$ & 1.1948 /present & $\begin{array}{l}\text { Statistic: u wind component } \\
\text { monthly mean. Level: } \\
\text { multiple levels* \& surface. } \\
\text { Unit: } \mathrm{m} / \mathrm{s}\end{array}$ \\
\hline $\begin{array}{l}\text { uwnd } 10 \mathrm{~m} . \mathrm{mon} \cdot \mathrm{mea} \\
\text { n.nc }\end{array}$ & $\begin{array}{l}\text { ftp://ftp.cdc.noaa.go } \\
\text { v/Datasets/ncep.rean } \\
\text { alysis.derived/surfac } \\
\text { e_gauss/uwnd10m. } \\
\underline{\text { mon.mean.nc }}\end{array}$ & $2.5^{\circ}$ & 1.1948 /present & $\begin{array}{l}\text { Statistic: u wind component } \\
\text { monthly mean. Level: } 10 \mathrm{~m} \text {. } \\
\text { Unit: } \mathrm{m} / \mathrm{s}\end{array}$ \\
\hline $\begin{array}{l}\text { uwndsur.mon.mean. } \\
\text { nc }\end{array}$ & $\begin{array}{l}\text { http://www.cdc.noaa } \\
\text {.gov/cdc/data.nmc.re } \\
\underline{\text { analysis.html }}\end{array}$ & $2.5^{\circ}$ & 1.1948 /present & $\begin{array}{l}\text { Statistic: u wind component } \\
\text { monthly mean. Level: } \\
\text { surface. Unit: } \mathrm{m} / \mathrm{s}\end{array}$ \\
\hline vwnd.mon.mean.nc & $\begin{array}{l}\underline{\text { http://www.cdc.noaa }} \\
\text {.gov/cdc/data.nmc.re } \\
\underline{\text { analysis.html }}\end{array}$ & $2.5^{\circ}$ & 1.1948 /present & $\begin{array}{l}\text { Statistic: } \mathrm{v} \text { wind component } \\
\text { monthly mean. Level: } \\
\text { multiple levels* \& surface. } \\
\text { Unit: } \mathrm{m} / \mathrm{s}\end{array}$ \\
\hline $\begin{array}{l}\text { vwnd10m.mon.mea } \\
\text { n.nc }\end{array}$ & $\begin{array}{l}\text { ftp://ftp.cdc.noaa.go } \\
\text { v/Datasets/ncep.rean } \\
\text { alysis.derived/surfac } \\
\text { e_gauss/vwnd10m. } \\
\text { mon.mean.nc }\end{array}$ & $2.5^{\circ}$ & 1.1948 /present & $\begin{array}{l}\text { Statistic: } \mathrm{v} \text { wind component } \\
\text { monthly mean. Level: } 10 \mathrm{~m} \text {. } \\
\text { Unit: } \mathrm{m} / \mathrm{s}\end{array}$ \\
\hline $\begin{array}{l}\text { vwndsur.mon.mean. } \\
\text { nc }\end{array}$ & $\begin{array}{l}\text { http://www.cdc.noaa } \\
\text { gov/cdc/data.nmc.re } \\
\underline{\text { analysis.html }}\end{array}$ & $2.5^{\circ}$ & 1.1948 /present & $\begin{array}{l}\text { Statistic: } \mathrm{v} \text { wind component } \\
\text { monthly mean. Level: } \\
\text { surface. Unit: } \mathrm{m} / \mathrm{s}\end{array}$ \\
\hline air2m.mon.mean.nc & $\begin{array}{l}\text { ftp://ftp.cdc.noaa.go } \\
\text { v/Datasets/ncep.rean } \\
\text { alysis.derived/surfac } \\
\text { e_gauss/air2m.mon. } \\
\text { mean.nc }\end{array}$ & $\begin{array}{l}\text { T62 Gaussian } \\
(192 \times 94 \text { pts } \\
\left.\sim 1.865^{\circ}\right)\end{array}$ & 1.1948/present & $\begin{array}{l}\text { Statistic: air temperature } \\
\text { monthly mean. Level: } 2 \mathrm{~m} \\
\text { Unit: } \mathrm{K}\end{array}$ \\
\hline air.mon.mean.nc & $\begin{array}{l}\text { http://www.cdc.noaa } \\
\text {.gov/cdc/data.nmc.re } \\
\text { analysis.html }\end{array}$ & $2.5^{\circ}$ & 1.1948 /present & $\begin{array}{l}\text { Statistic: air temperature } \\
\text { monthly mean. Level: } \\
\text { multiple levels** }\end{array}$ \\
\hline
\end{tabular}




\begin{tabular}{|c|c|c|c|c|}
\hline & & & & Unit: $\mathrm{K}$ \\
\hline sst.mean.nc & $\begin{array}{l}\text { http://www.cdc.noaa } \\
\text { gov/cdc/data.nmc.m } \\
\text { arine.html }\end{array}$ & $2.5^{\circ}$ & 1.1948 /present & $\begin{array}{ll}\text { Statistic: sea } & \text { surface } \\
\text { temperature } & \text { monthly } \\
\text { mean. Level: } & \text { surface. } \\
\text { Unit: }{ }^{\circ} \mathrm{C} & \end{array}$ \\
\hline olr.mon.mean.nc & $\begin{array}{l}\text { http://www.cdc.noaa } \\
\text {.gov/cdc/data.interp } \\
\text { _OLR.html }\end{array}$ & $2.5^{\circ}$ & $\begin{array}{l}1.1948 \\
\text { /present, but } \\
\text { gap:17.3.1978/3 } \\
1.12 .1978\end{array}$ & $\begin{array}{l}\text { Statistic: outgoing longwave } \\
\text { radiation monthly mean. } \\
\text { Level: other. Unit: not } \\
\text { specified }\end{array}$ \\
\hline pr_wtr.mon.ltm.nc & 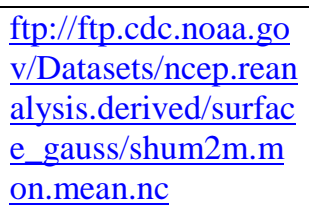 & $2.5^{\circ}$ & 1.1948 /present & $\begin{array}{l}\text { Statistic: precipitable water } \\
\text { content long term monthly } \\
\text { mean. Level: all levels as } \\
\text { one. Unit: } \mathrm{kg} / \mathrm{m}^{2}\end{array}$ \\
\hline \multicolumn{5}{|l|}{ B) ECMWF data } \\
\hline File name & Source & Resolution & Period & File description \\
\hline $\begin{array}{l}\text { SINLEVXX.DAT } \\
\text { (where } X X \text { is the 2- } \\
\text { digit year between } \\
1979 \text { and 1993) }\end{array}$ & $\begin{array}{l}\text { ECMWF ERA-15 } \\
\text { Re-Analysis Sample } \\
\text { Data (available on } \\
\text { CD-Rom) }\end{array}$ & $\begin{array}{l}2.5^{\circ} \text { (144 by } \\
73 \text { grid points) }\end{array}$ & 1979/1993 & $\begin{array}{l}\text { Statistic: } 10 \mathrm{~m} \quad \mathrm{U} \quad \& \quad \mathrm{~V} \\
\text { components of } \\
{[\mathrm{m} / \mathrm{s}], 2 \mathrm{~m} \text { Temperature }[\mathrm{K}],} \\
\text { total Cloud [0-1], total } \\
\text { Precipitation [mm/day], } \\
\text { Evaporation [mm/day] }\end{array}$ \\
\hline $\begin{array}{l}\text { UPPAIR YY.DAT } \\
\text { (where } Y Y \text { is the 2- } \\
\text { digit year between } \\
1979 \text { and 1993) }\end{array}$ & $\begin{array}{l}\text { ECMWF ERA-15 } \\
\text { Re-Analysis Sample } \\
\text { Data (available on } \\
\text { CD-Rom) }\end{array}$ & $\begin{array}{l}2.5^{\circ} \text { (144 by } \\
73 \text { grid points) }\end{array}$ & $1979 / 1993$ & 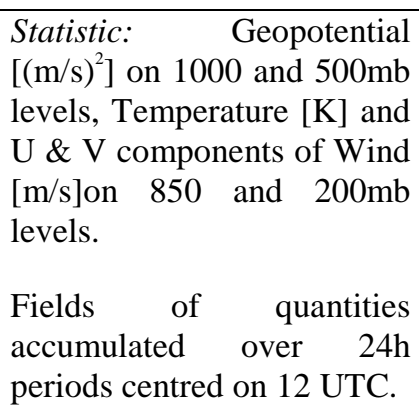 \\
\hline
\end{tabular}

Table 2: A) NCEP / NCAR Reanalysis data and B) ECMWF Reanalysis data, *Multiple levels: 1000, 850, 700, 500, 300, 250, 200, 100 , and $50 \mathrm{hPa} / \mathrm{mbs}$, ** Multiple levels: 1000, 925, 850, 700, 600, 500, 400, 300, 250, 200, 150, 100, 70, 50, 30, $20 \mathrm{and} 10 \mathrm{hPa} /$ mbs

\subsection{The topographical database and the 'Roughness Parameter'}

A Digital Elevation Model (DEM) at a resolution of $0.08^{\circ}$ lat / lon grid $(\sim 1 \mathrm{~km})$ will be used by the user interface. The DEM is available from NOAA GLOBE Project in IDRISI compatible raster format. This layer will be of direct benefit in the calculation of an upwind terrain roughness parameter (UTRP), an empirical index which will give an indication of the suitability of a potential site, given local wind turbulence. It consists of an index attached to each land pixel resulting from the combination of two subsets: 
- $\quad$ roughness maps $(\mathrm{R})$ : the standard deviation of the altitude of neighboring pixels (normalized by distance from pixel) is computed for each pixel for 8, 45 degree sectors. A special filter shall be developed for this purpose as shown in Figure 2. The distribution obtained is then normalized by the median and truncated to twice the median so that $\mathrm{R}$ stays between 0 and 1 .

- $\quad$ upwind maps (U): map of frequency of occurrence of given wind direction (wind rose) in 45 degree steps. $\mathrm{U}$ is between 0 and $1(100 \%)$, the sum of $\mathrm{R}$ over the 8 sectors is equal to 1 .

The procedure for the calculation of the UTRP is as follows: Firstly, a Filter grid (also known as a Kernel) is created outside of IDRISI (this will be made using either Quick Basic or Fortran computing languages). The Filter Kernel is simply an ASCII text file consisting of $n$ rows by $n$ columns, where $n$ is the chosen dimension of the filter. There are also two headers lines giving the number of rows and columns in the file respectively (see example below). Morphologically, ${ }^{n} / 2$ represents the distance (relative to scale of input image) that the roughness parameter will cease to be influenced by an upstream obstacle (i.e. mountain ridge). Thus, for a $0.08^{\circ}$ lat $/$ lon grid $(\sim 1 \mathrm{~km})$ grid, a filter kernel of 7 by 7 means that the influence of a mountain ridge on the roughness parameter ceases $3.5 \mathrm{~km}$ downwind of it (this is just a simplified example, in reality, it will be much greater). The filter kernel also needs to be created in such a way, that all eight compass point directions (namely N, NE, E, SE, S, SW, W and NW) are represented by eight different filter kernels. Each of the eight kernels will have zero values for all directions, other than its relevant compass direction. For example, the $\mathrm{N}$ compass kernel might look like:

\begin{tabular}{|lllllll|}
\hline 0.00 & 0.00 & 0.02 & 0.02 & 0.02 & 0.01 & 0.00 \\
\hline 0.00 & 0.00 & 0.04 & 0.05 & 0.04 & 0.00 & 0.00 \\
\hline 0.00 & 0.00 & 0.00 & 0.30 & 0.00 & 0.00 & 0.00 \\
\hline 0.00 & 0.00 & 0.00 & 0.50 & 0.00 & 0.00 & 0.00 \\
\hline 0.00 & 0.00 & 0.00 & 0.00 & 0.00 & 0.00 & 0.00 \\
\hline 0.00 & 0.00 & 0.00 & 0.00 & 0.00 & 0.00 & 0.00 \\
\hline 0.00 & 0.00 & 0.00 & 0.00 & 0.00 & 0.00 & 0.00 \\
\hline
\end{tabular}

In the above example, the first two numbers represent the number of rows and columns in the Filter Kernel (i.e. 7 by 7 ). Only pixels in the directions between $337.5^{\circ}$ and $22.5^{\circ}$ (the $45^{\circ}$ surrounding compass point $\mathrm{N}$, the algorithm will smooth the $45^{\circ}$ influence) are given values, which all sum to 1.00. All other points are given 0.00. Eight files such as the above are created for each compass point direction. The center pixel in our example has been given a value of 0.50 , meaning $50 \%$ of its initial value will be kept in the final new value.

The second step involves running of the FILTER module in IDRISI eight times. Each new pixel value is calculated by placing the center pixel of the kernel (red pixel marked in Figure 2) over each individual pixel and multiplying it and the surrounding pixels by the appropriate overlying value of the kernel, and summing the total. Because the sum of the kernel adds to 1.0, we do not get a change in total absolute data value for the whole image, but merely a type of "smoothing" occurs instead.

The penultimate step involves normalizing the resulting eight maps. This is done simply by finding the median and truncating each distribution to twice its value, ensuring that the UTRP stays between 0 and 1. 
The final stage is to simply multiply each directional roughness map by the frequency of wind for that direction, sum the result, and subtract it from 1. Therefore, an ideal site (e.g. island peak surrounded by sea will give a value close to 1.0 , a coastal mountain range (with $50 \%$ onshore winds) a value of 0.5 .

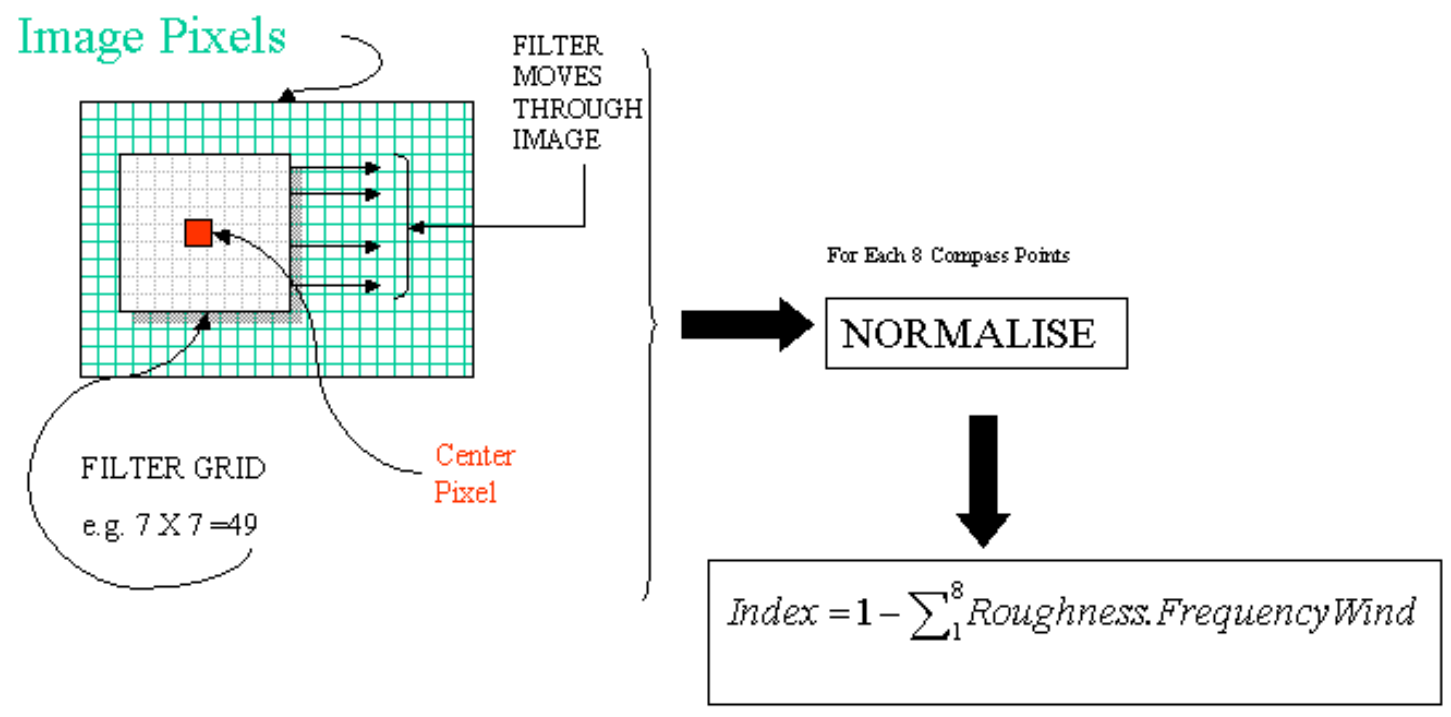

Figure 2 An illustration of the procedure for the calculation of the Roughness Parameter, based on the IDRISI $0.08^{\circ}$ resolution. See text for details.

An appropriate land cover map and world vector format map will also be used. At a later stage, it will be necessary to include seismic potential maps, in order to locate regions of maximum / minimum probability of earth tremors.

\section{MESOSCALE MODELING}

A contract for the analysis of the performance of mesoscale modeling of the surface wind flow at the VLT site has been awarded to the Meteorological Institute of Munich at Ludwig Maximilian University. The project aims at estimating the efficiency of the mesoscale model MM5 in modeling the flow above the Paranal area in view of forecasting the occurrence of bad observing conditions (bad seeing) linked to a particular (NE) wind direction

\subsection{Technical aspects about MM5}

The size of the outermost domain has almost no effect on the computational costs, so there is no way to optimize calculation time by a smaller outer domain. The vertical resolution is 38 layers, upper boundary is $100 \mathrm{hPa}$. The distance between the layers can be chosen arbitrarily by the users. In these simulations, the distance between layers is about $100 \mathrm{~m}$ in the lower atmosphere increasing to about $700 \mathrm{~m}$ in the upper atmosphere so that the resolution is the highest near the ground. MM5 is driven by ECMWF data from 00 UTC, 6 UTC etc., linearly interpolated in between. The data introduced at the boundaries does not reach the innermost domain, at least on the advection time scale, in our cases.

\subsection{Parameterization in MM5}

Convection, in $27 \mathrm{~km}$ and $9 \mathrm{~km}$ domain (by Grell) is treated explicitly in $3 \mathrm{~km}$ and $1 \mathrm{~km}$ domain. Moisture is simple (Reisner-1), clouds are not a major feature at Paranal. Radiation uses thermal (RRTM) solar model by MM5, takes the slope of the area into consideration. Because of the scale of the flow, different parameterizations of radiations are not 
supposed to have influence. The boundary layer, maybe the most interesting parameterization, called Geyno-Seaman, uses turbulent kinetic energy (TKE) to calculate vertical diffusion, supposed to be the most sophisticated parameterization in MM5. However parameterization influences only the wind shear of the lowest $\sim 500 \mathrm{~m}$ and should not change wind direction.

\subsection{Modeling strategy}

First a 'classification' of $500 \mathrm{hPa}$ patterns was conducted for the period 1998-2001, in the Paranal area. 11 typical patterns were found, namely: low offshore Chile, intense trough, weak trough, wide trough, westerly flow, perturbed westerly flow, transition westerly flow to ridge, south-westerly flow, weak gradient, high pressure and ridge. It was found that these synoptic situations did not have a clear influence on observing conditions at Paranal. It was concluded that there is no significant correlation between the behavior of the flow at Paranal (and therefore 'seeing') and the 500 $\mathrm{hPa}$ patterns, thus demonstrating the mesoscale nature of the problem.

A minimum of 20, twenty-four hour simulation for Paranal will be performed, including 10 cases where the wind turned from northwest to northeast during the night and ten others where it didn't. The results from an inter comparison will give a fairly good indication with respect to the usefulness of such forecasts. A success of the study could lead to an operational forecast of the risk of bad seeing occurrence at the observatory. In such an operational application, the runs could only start at 6UT after reception of the ECMWF 00UT analysis and forecasts. It is presumably necessary to start that early because the model needs some time to adjust to be ready to forecast the conditions of the next night (a night is defined as 0UT-10UT). The forecast of the night to be analyzed consists of the MM5 output from 0UT to 10UT the next day $(\mathrm{H}+18$ to $\mathrm{H}+28)$ in steps of 1 hour. The complete forecast should be available at the beginning of the night $(\mathrm{H}+18)$. The model should thus run twice faster than real time.

The further application of this work to ELT site surveys is straightforward. The MM5 output for typical synoptic situations can be used to refine the computation of the upwind terrainroughness parameter (UTRP) described in the previous section.

\section{REFERENCES}

1. P. Dierickx et al., "Eye of the beholder: designing the OWL, SPIE 4840-24, 2002

2. M. Sarazin and A. Tokovinin, "The statistics of isoplanatic angle and adaptive optics time constant derived from DIMM data," Beyond Conventional Adaptive Optics, Venezia, 7-10 May 2001, ESO Conference Proceedings.

3. E. di Folco et al., "Atmospheric and internal turbulence measured on the very large telescope interferometer with VINCI," SPIE 4838-35, 2002

4. A. Tokovinin et al., "MASS: a monitor of the vertical turbulence distribution," SPIE 4839-102, 2002 